\title{
Corneal dystrophy, classification, and phototherapeutic keratectomy. A case report
}

\section{Distrofia corneal, clasificación y queratectomía fototerapéutica. Reporte de un caso}

\author{
Taimi Cárdenas-Díaz ${ }^{1 *}$, M. Teresa González-Hernández¹, Melissa Enamorado-Fernández², \\ Michel Guerra-Almaguer ${ }^{1}$, Juan P. Vargas-Vergara', and M. Fernanda González-Ortega ${ }^{1}$ \\ ${ }^{1}$ Ophthalmology Department, Ramón Pando Ferrer Cuban Institute of Ophthalmology; ${ }^{2}$ Victoria de Girón School of Medicine, University of Havana. \\ La Habana, Cuba
}

\begin{abstract}
Objective: To present a case of epithelial basement membrane dystrophy according to the IC3D Classification of corneal dystrophies Edition 2 and results after a phototherapeutic keratectomy. Clinical case: A 61-year-old female with decreased visual acuity in both eyes, corneal opacities, subepithelial lines (map-like) in the central area of both corneas. Epithelial basement membrane dystrophy was diagnosed by confocal microscopy, and a phototherapeutic keratectomy was performed, achieving good corneal transparency, a normal confocal microscopy and visual recovery. Conclusions: The IC3D Classification of corneal dystrophies IC3D Edition 2 facilitated the diagnosis of the case. The good morphological result, the significant visual acuity gain and the corneal regularity evidenced by Sirius ${ }^{\circledR}$ tomography demonstrate that phototherapeutic keratectomy is an effective treatment for epithelial basement membrane dystrophy.
\end{abstract}

Keywords: Corneal dystrophy. IC3D Classification Edition 2. Phototherapeutic keratectomy.

\section{Resumen}

Objetivo: Presentar un caso de distrofia de la membrana basal epitelial según el sistema de clasificación y la nomenclatura de las distrofias corneales IC3D-Edición 2, así como los resultados de la queratectomía fototerapéutica. Caso clínico: Mujer de 61 años con opacidades corneales, disminución de la visión en ambos ojos y líneas curvadas en forma de mapas subepiteliales ubicadas en el área central de ambas córneas. Se le diagnóstico una distrofia de la membrana basal con apoyo de la microscopía confocal y se le realizó queratectomía fototerapéutica, con lo que se obtuvo una buena transparencia corneal, microscopía confocal normal y recuperación visual. Conclusiones: El sistema de clasificación y nomenclatura de las distrofias corneales IC3D-Edición 2 facilitó el diagnóstico del caso. El buen resultado morfológico, la significativa ganancia visual y la regularidad corneal por tomógrafo Sirius ${ }^{\circledR}$ demuestran que la queratectomía fototerapéutica es un tratamiento efectivo para la distrofia de la membrana basal epitelial.

Palabras clave: Distrofia corneal. Clasificación IC3D-Edición 2. Queratectomía fototerapéutica.

Correspondence:

*Taimi Cárdenas-Díaz Canal 3116

Reparto Antonio Maceo, Municipio Cerro Date of reception: 11-06-2020

C.P. 10400, La Habana, Cuba Date of acceptance: 09-09-2020

E-mail: taimicar@infomed.sld.cu

2604-1731/@ 2020 Sociedad Mexicana de Oftalmología. Published by Permanyer. This is an open access article under the CC BY-NC-ND license (http://creativecommons.org/licenses/by-nc-nd/4.0/). 


\section{Introduction}

In 1884, Wilhelm Erb introduced the term "dystrophy" into the medical literature, which derives from the Greek dys, bad, difficult, and trophe, nutrition. In 1890, Groenouw published an article in which he described two patients with corneal nodules, one of them with granular corneal dystrophy and the other with macular corneal dystrophy. Biber published his thesis on lattice corneal dystrophy in 1890, and Fuchs used the term "corneal dystrophy" to refer to ophthalmic disease and postulated that dystrophic tissues were the result of a lack of nutrition, hormones, blood supply, and innervation. This denomination was maintained by Uhthoff and Yoshida. However, more than a century ago, Bucklers published the first classification of corneal dystrophies when he described the differences between granular, lattice, and macular corneal dystrophies. Before the 1970s, new corneal dystrophies were identified and characterized by their clinical appearance, sometimes aided by light microscopic histopathology. In some cases, the description was based on data from a single family; in others, a new dystrophy was mistakenly classified as a variant of an already known one. The knowledge base has grown exponentially since these first descriptions, some from more than a century ago. The development of genetic studies has revolutionized knowledge, clarified inaccuracies in the nomenclature of dystrophies and made the phenotypic classification obsolete, since alterations in different genes can give rise to a single phenotype, while different changes in a gene can originate different phenotypes ${ }^{1}$.

In April 2005, during the World Congress meeting of The Cornea Society, it was concluded that the problems of the nomenclature made it unsuitable for dystrophies, so the International Committee for Classification of Corneal Dystrophies was formed (IC3D), which would have the responsibility of developing a new nomenclature. In 2014 the classification, known as IC3D-Edition 2, was updated again, incorporating genetic, histopathological and clinical information. Publications between 2008 and 2014 were considered, and templates and anatomical classification were updated ${ }^{1}$.

Based on a review of the cellular origin of corneal dystrophies, this modified anatomical classification is proposed: 1) epithelial and subepithelial dystrophies; 2) epithelial-stromal TGFBI dystrophies; 3) stromal dystrophies; and 4) endothelial dystrophies. Epithelial recurrent erosion dystrophies now include a number of strongly distinctive epithelial dystrophies (Franceschetti corneal dystrophy, Dystrophia Smolandiensis, and Dystrophia Helsinglandica), but they have to be differentiated from other dystrophies, such as those induced by $T G B F I$, which are often associated with recurrent epithelial erosions. The four descriptive categories (C) continue to be used to indicate the level of evidence that reinforces the existence of a possible corneal dystrophy':

C1: A well-defined corneal dystrophy in which the gene has been mapped and identified and specific mutations are known.

C2: A well-defined corneal dystrophy that has been mapped to 1 or more specific chromosomal loci, but the

gene(s) remains to be identified.

C3: A well-defined corneal dystrophy in which the disorder has not yet been mapped to a chromosomal locus.

C4: This category is reserved for a suspected new, or previously documented, corneal dystrophy, although the evidence for it, being a distinct entity, is not yet convincing ${ }^{1}$.

The category of a dystrophy varies over time as new knowledge is gained, and in the long term all valid dystrophies should reach category $1^{1}$.

This new classification system has an anatomical basis, so that dystrophies are classified based on the predominantly affected layer: epithelial and subepithelial, epithelial-stromal, stromal and endothelial'.

Most of the names of the dystrophies resemble the current nomenclature, while the dystrophies with a common genetic basis have been grouped together. Each template provides the key genetic, clinical and pathological features characteristic of that dystrophy, and is assigned a level of evidence 1, 2, 3 or 4 depending on the information available about it ${ }^{1}$.

This new nomenclature of corneal dystrophies is more precise, informative and, at the same time, easier to use'.

\section{Clinical case}

This is the case of a 61-year-old woman with a 1-year history of progressive visual acuity decrease in both eyes. Uncorrected visual acuity in the right eye (OD) was 0.1 and in the left eye (OS) 0.2 in the Snellen chart; with correction it was 0.4 with $+3.00-1.50 \times 20^{\circ}$ in the $\mathrm{OD}$ and 0.4 with $+1.75-2.75 \times 145^{\circ}$ in the OS. Intraocular pressure was $10 \mathrm{mmHg}$ in the OD and $11 \mathrm{mmHg}$ in the OS, adjusted according to pachymetry. Biomicroscopic examination showed both eyes with opacities in 
curved lines, in the form of subepithelial maps, located in the central area of both corneas (Fig. 1). There were no other alterations in the anterior and posterior segments.

A corneal tomography was performed with a Sirius ${ }^{\circledR}$ tomography from NIDEK (Fig. 2A), in which the corneal irregularity was observed in the tangential anterior map in both eyes (in the six maps of each eye it is the upper right). The refractive analysis of the OD showed a cylinder of -2.52 diopters (D), and shape indices showed a $P$ (shape factor that derives from the eccentricity, $P=1-e^{2}$ ) that, although it is $<1$, it is high, of 0.90 at $6 \mathrm{~mm}$ on the anterior surface, with a RMS (Root Mean Square) of 0.16 . In the OS, the refractive analysis showed a cylinder of $-3.51 \mathrm{D}$ and a longitudinal spherical aberration (LSA) of $-8.21 \mathrm{D}$. The shape indices showed a $P$ of -0.13 at $6 \mathrm{~mm}$ on the anterior surface, with a RMS of 0.28 .

In addition, a confocal microscopy (CS4, NIDEK Technologies, Padova, Italy) was performed in both eyes, which showed a disorganized epithelium, without observing the basal epithelium, as well as the surface epithelium, as can be seen in the first three columns of rows $A$ and $C$ of Figure 3 . There were no changes in the stroma or the endothelium (columns 4 and 5 of the same rows).

This patient was diagnosed with an epithelial basement membrane dystrophy by slit lamp biomicroscopy of the anterior segment and confocal microscopy, although genetic tests were not performed as they are highly expensive.

A phototherapeutic keratectomy (PTK) was planned, first in the OS and later in the OD, with the aim of regularizing the corneal surface and making it more uniform and transparent. Throughout the ablation, the corneal surface was maintained with mask solution (viscoelastic solution previously prepared with $1 \mathrm{ml}$ of sodium hyaluronate diluted in $5 \mathrm{ml}$ of saline solution). Subsequently, $0.02 \%$ mitomycin $\mathrm{C}$ was applied for 15 seconds, followed by bandaging with a therapeutic lens and instillation of antibiotic and corticosteroid eye drops (Fig. 4). The contact lens was removed when the cornea was fully epithelialized, 6 days later.

One year after treatment, the corneas remained transparent and the patient had a better uncorrected visual acuity in both eyes, of 0.8 in the Snellen chart, and 1.0 corrected with $+1.00-0.50 \times 55^{\circ}$ in the OD and $+1.00-0.75 \times 95^{\circ}$ in the OS. In addition, there was a more regular corneal surface in both eyes, as observed in the Sirius ${ }^{\circledR}$ tangential anterior map (in the six maps of each eye, it is the upper right), as well as in the

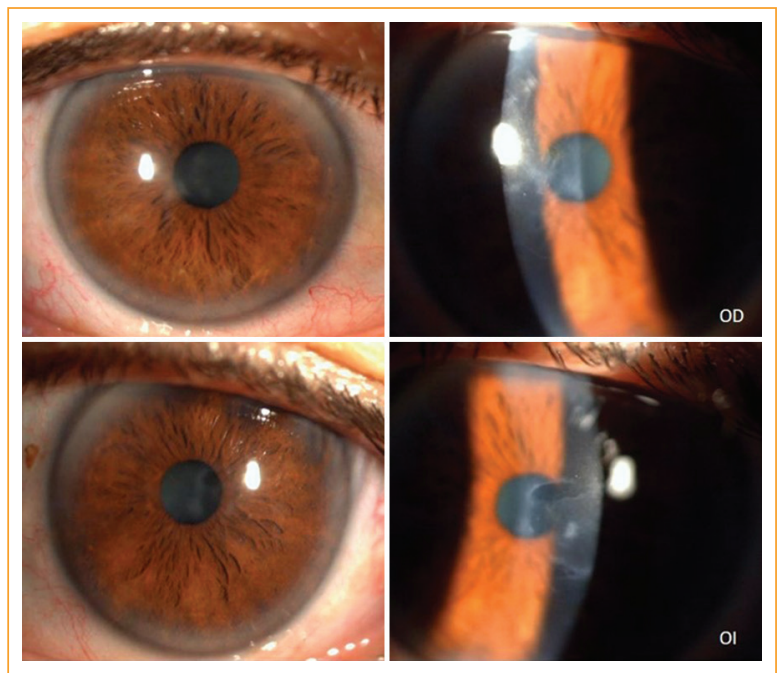

Figure 1. On biomicroscopic examination, both eyes showed curvilinear lines, in the form of subepithelial maps, located in the central area of both corneas.

refractive analysis, with an improvement of $P$ shapes and RMS, with a decrease of the cylinder to $-0.11 \times$ $35^{\circ}$ in the OD and $-0.52 \times 100^{\circ}$ in the OS (Fig. 2 B). On the other hand, confocal microscopy showed a satisfactory recovery of the corneas, a better defined epithelium with very reflective nuclei surrounded by a hypo-reflective halo that stands out on a homogeneous cytoplasm, and keratocyte activation in the stroma (Fig. 3).

\section{Discussion}

Corneal dystrophies are typically bilateral, symmetric, slowly progressive hereditary diseases that are not related to environmental or systemic factors, and although genetic tests are required for confirmation ${ }^{1}$, taking into account the new classification system, there was no doubt that this patient had an epithelial and subepithelial dystrophy, and within this group, it was a basement membrane dystrophy.

Epithelial basement membrane dystrophy, also known as map-dot-fingerprint dystrophy and Cogan microcystic epithelial dystrophy, is the most frequent anterior corneal dystrophy, with a higher incidence in females and onset in adult life, being rare in children. Most cases do not have a documented inheritance and are considered degenerative or post-traumatic; however, isolated familial cases associated with specific mutations of the TGFBI gene, locus $5 q 31$, inherited with an autosomal dominant pattern, have been reported, 
A

B

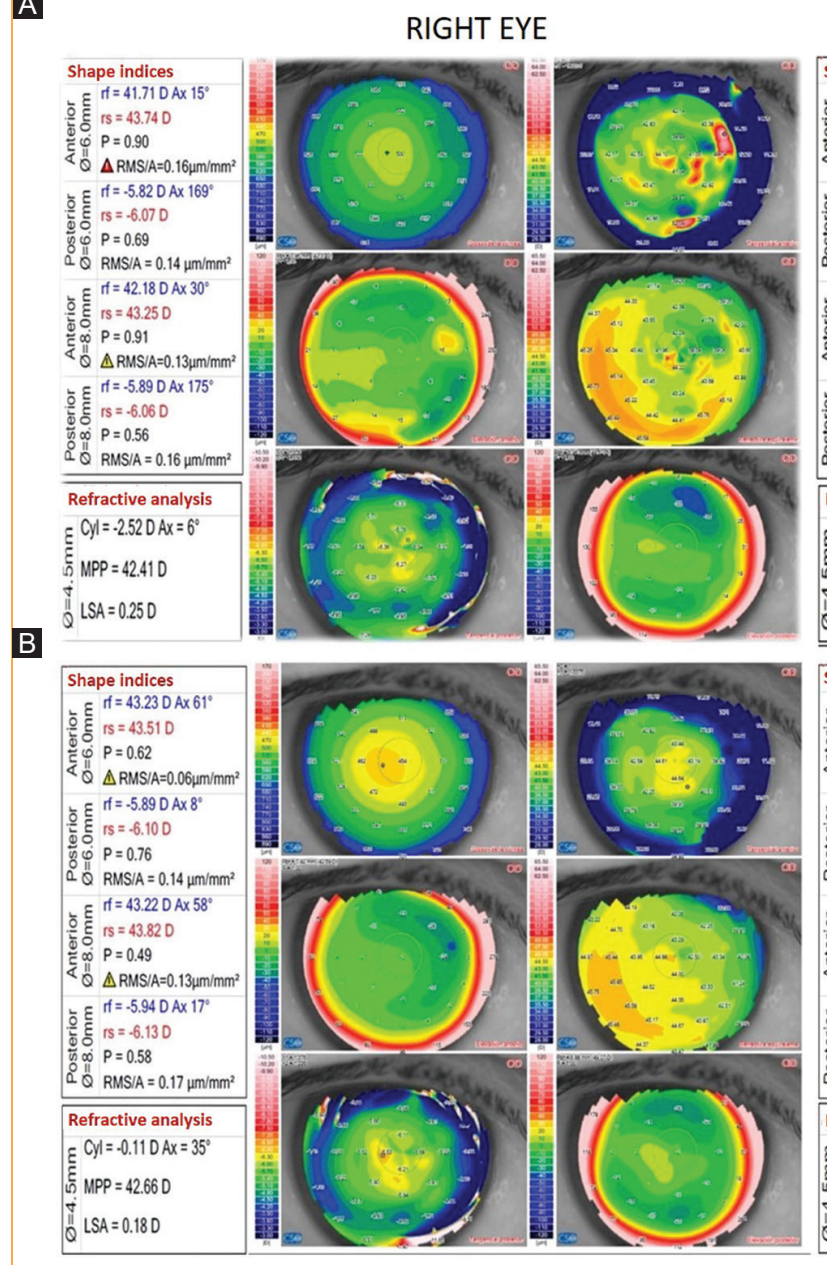

\section{LEFT EYE}

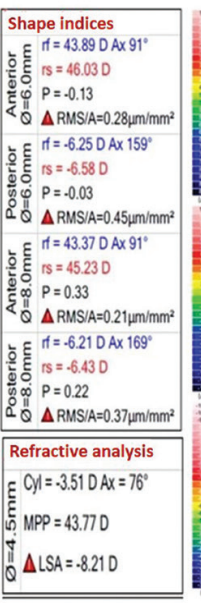

Shape indices

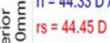

要 $P=0.47$

Q RMS $/ \mathrm{A}=0.03 \mu \mathrm{m} / \mathrm{mm}^{2}$

E $\mathrm{rf}=-5.99 \mathrm{DAx} 179^{\circ}$

要政 $=-6.26 \mathrm{D}$

0.44

Q. $Q$ R $\triangle$ MS $/ A=0.15 \mu \mathrm{m} / \mathrm{mm}$

E If $=44.44 \mathrm{D} \mathrm{Ax} 72^{\circ}$

등 $\mathrm{Is}=44.51 \mathrm{D}$

P $P=0.41$

Q RMS $/ \mathrm{A}=0.07 \mu \mathrm{m} / \mathrm{mm}^{2}$

if $=-6.03 \mathrm{D} \mathrm{Ax} 2^{\circ}$

$\varepsilon_{\mathrm{F}} \mathrm{if}=-6.22 \mathrm{D}$

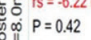

Q $Q$ RMS/A $=0.15 \mu \mathrm{m} / \mathrm{mm}^{2}$

Refractive analysis $\mathrm{Cyl}=-0.52 \mathrm{DAx}=100^{\circ}$ $M P P=43.52 D$

ISA $=0.32 D$
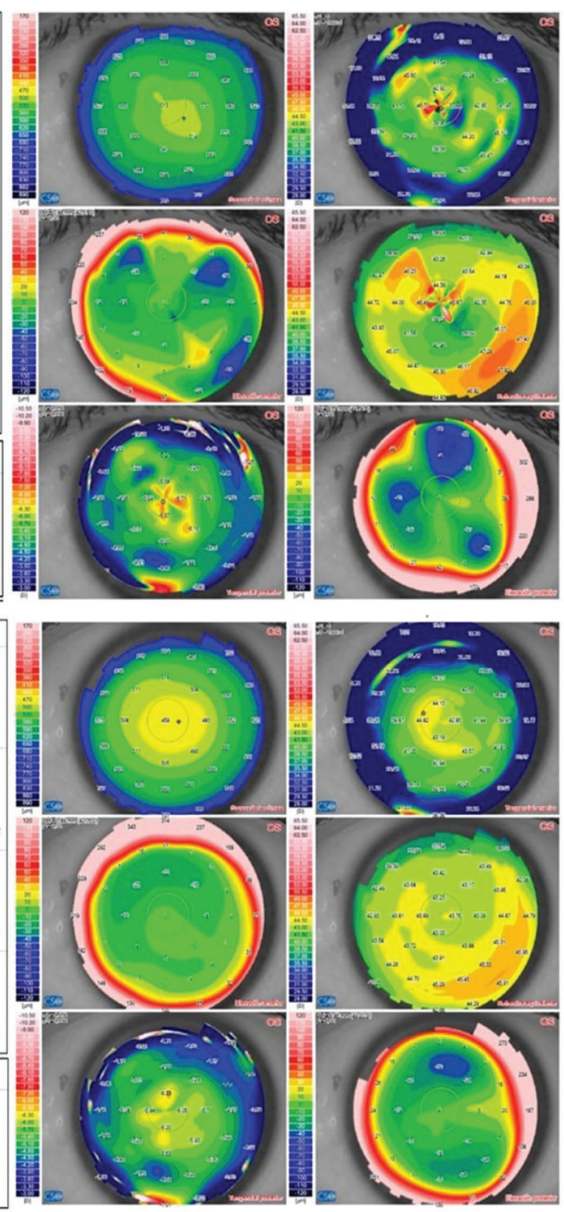

Figure 2. Pachymetry and topography maps of both eyes obtained with the Sirius ${ }^{\circledR}$ tomograph, with summary measurements. A: preoperatively, the corneal irregularity in both eyes is observed in the tangential anterior map (of the six maps of each eye, it is the upper right), as well as in the refractive analysis and the shape indices (OD with a cylinder of $-2.52 \mathrm{D}$, a high $\mathrm{P}$ of 0.90 at $6 \mathrm{~mm}$ on the anterior surface with an RMS of 0.16 , and $\mathrm{OS}$ with a cylinder of $-3.51 \mathrm{D}, \mathrm{LSA}$ of $-8.21 \mathrm{D}$ and a negative $\mathrm{P}$ of -0.13 at $6 \mathrm{~mm}$ on the anterior surface, with an RMS of 0.28 ).

B: postoperatively, there is a more regular corneal surface in both eyes, as observed in the tangential anterior map of both eyes, as well as in the refractive analysis, with an improvement of the P shapes and RMS indices, with a decrease of the cylinder to $-0.11 \times 35^{\circ}$ in the $\mathrm{OD}$ and to $-0.52 \times 100^{\circ}$ in the $\mathrm{OS}$.

so they are included in category $1^{1}$. Its location and degree fluctuate over time. Patients with this condition have asymptomatic or recurrent erosions, with pain, tearing, and blurred vision; the latter due to the irregular astigmatism it causes, as in the case presented in this article. Furthermore, maps show irregular islands of thickened epithelium, dots that appear as rounded or comma-shaped irregular opacities, and parallel, curvilinear lines resembling a fingerprint and a subepithelial bleb pattern like pebbled glass ${ }^{2}$.

Regarding treatment, it can range from observation, when it is asymptomatic, conservative measures with lubricants, artificial tears and treatment of meibomian gland dysfunction, if necessary, to surgical treatment such as lacrimal punctal occlusion, debridement of the aberrant epithelium, superficial keratectomy and excimer laser; the latter with great effectiveness, since in addition to eliminating the anomalous material, it leaves a smooth surface for the regeneration of the basement membrane ${ }^{2}$.

Phototherapeutic keratectomy, the treatment chosen for our patient, has been used as a therapeutic tool for corneal surface alterations, such as opacities and irregularities, for more than 10 years $^{3}$. Its objectives are to remove the altered corneal tissue, to achieve a regular corneal surface that does not generate a large 


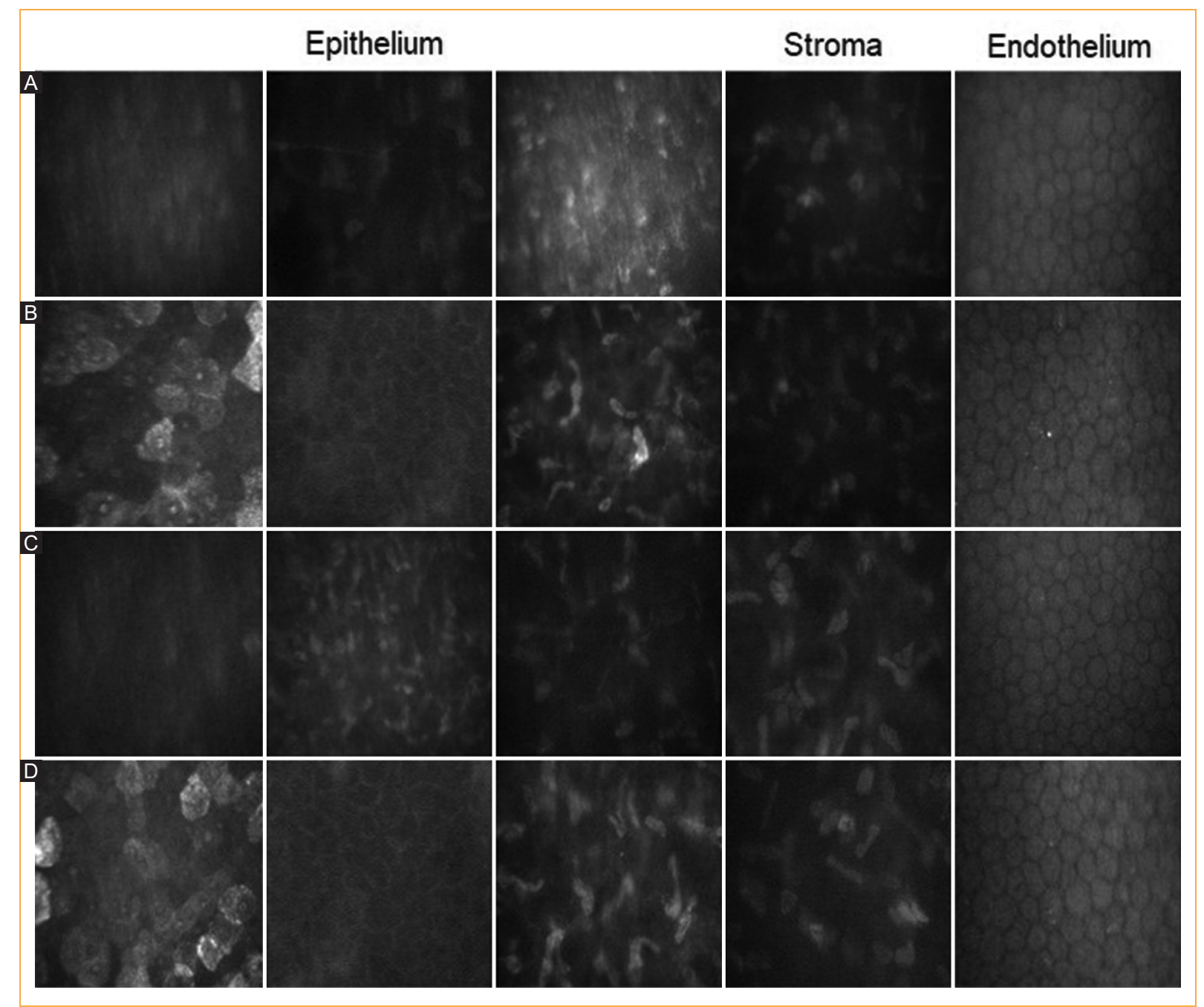

Figure 3. A and C: preoperative confocal microscopy images of the OD and OS, respectively. The first three columns show a disorganized epithelium, there are no visible superficial cells with well-defined borders and very reflective nuclei surrounded by a hypo-reflective halo, and neither are the basal cells, which are smaller and found in greater numbers. The stroma (fourth column) and endothelium (fifth column) show no visible alterations. B and D: postoperative images of the $\mathrm{OD}$ and $\mathrm{OS}$ at one year. The first three columns show a better defined epithelium, with very reflective nuclei surrounded by a hypo-reflective halo that stands out on a homogeneous cytoplasm. The stroma (fourth column) shows keratocyte activation and the endothelium (fifth column) shows no alterations.

wound healing reaction, and to promote the correct adherence of the epithelium ${ }^{4}$.

The most frequent indication of PTK is recurrent epithelial corneal erosions, which can be of unknown etiology, such as traumatic or associated with a basement membrane dystrophy or other corneal dystrophies that may have it as a main symptom ${ }^{5}$.

Standard PTK treatment involves careful mechanical de-epithelialization over the pathological area and then application of a 3-6 $\mu \mathrm{m}$ deep excimer laser ablation on Bowman's membrane. The epithelium must be removed in the entire central pupillary area so as not to induce asymmetries or irregularities with Bowman's membrane ablation ${ }^{6}$.

The primary success of this technique is around $68 \% 7,8$. Results appear to be slightly better in post-traumatic than dystrophic cases. Furthermore, the superiority of combined manual and laser treatment over conventional manual treatment has been proven in a prospective randomized study carried out at the beginning of the PTK era ${ }^{6}$. It has also been found that most recurrences appear within the first 4 postoperative months. If it does not recur initially, the technique seems to maintain its effect over the years. In addition, 

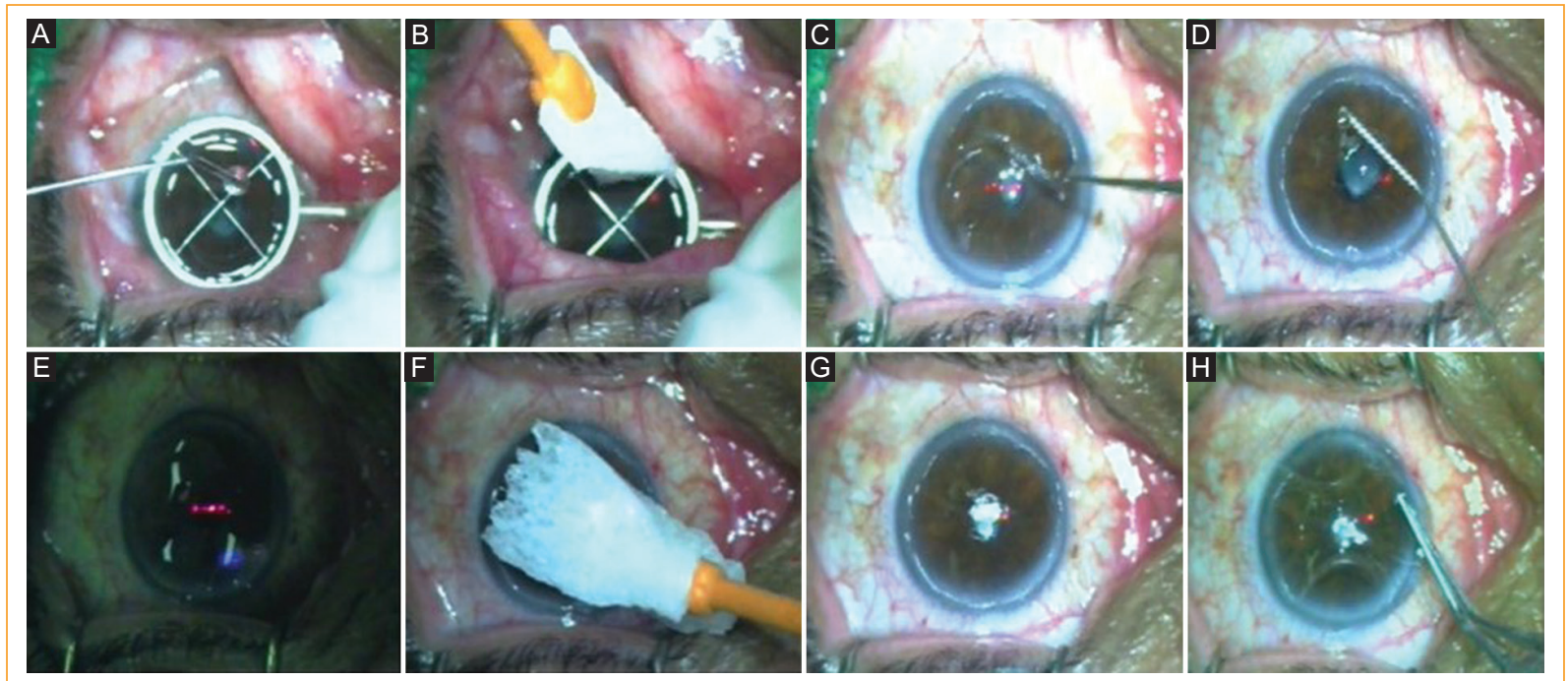

Figure 4. Sequential photography of phototherapeutic keratectomy of the OS. A and B: container with $20 \%$ alcohol applied for 20 seconds to allow de-epithelialization. C: the epithelium is manually removed. D: placement of mask solution. E: laser ablation. F: $\mathbf{0 . 0 2} \%$ mitomycin $\mathbf{C}$ applied for 15 seconds. $\mathbf{G}$ and $\mathbf{H}$ : end of the procedure with the cornea ablated and placement of a soft therapeutic contact lens.

PTK is also superior to other therapeutic alternatives that show a success rate of $40-50 \%$ for de-epithelialization followed by YAG laser micro puncture and $60 \%$ for mechanical micro puncture, although there is no study that has compared them prospectively. If the syndrome recurs after a first PTK, retreatment with a second PTK appears to significantly reduce recurrences. The results also support the suitability of combining transepithelial PTK with photorefractive keratectomy, when the objective is to achieve deepithelization reaching Bowman's membrane ${ }^{9}$.

Map-dot-fingerprint dystrophy is the second most common indication for $\mathrm{PTK}^{10}$. Clinically, the changes are detected in decreasing order of prevalence: map, dots and fingerprint. It is caused by a disorderly production of the basement membrane and usually induces frequent refractive changes, mild to moderate blurring sensation and recurrent erosions. Phototherapeutic treatment can be transepithelial (flat ablation $7 \mathrm{~mm}$ in diameter and approximately $55 \mu \mathrm{m}$ deep) if the biomicroscopic appearance of the epithelium is regular. When the epithelial surface is clearly irregular, then it may be a better option to mechanically debride the epithelium using a scarifier or spatula. Once on Bowman's membrane, the goal is to remove about $10 \mu \mathrm{m}$ of tissue by flat ablation. Postoperative recovery is relatively fast, and refractive stability and a decrease in symptoms are observed after 2 months. Overall, the results are very satisfactory: refraction typically stabilizes early, corrected visual acuity improves $(76 \%)$, and erosions cease $(95 \%)$. However, a certain refractive change may occur despite the superficiality of Bowman's membrane ablation, so the preoperative information discussed with the patient should include this aspect ${ }^{11}$. When it relapses, it does so in the first 6-9 months ${ }^{10}$.

\section{Conclusions}

The case presented shows that the IC3D classification of corneal dystrophies and nomenclature system with an anatomical basis, that is, according to the predominantly affected layer, facilitates the diagnosis, in this case, of basement membrane dystrophies. On the other hand, by achieving a good morphological result, showed by corneal transparency and confocal microscopy, and a significant visual recovery at one year of follow-up, as well as corneal regularity demonstrated by the Sirius ${ }^{\circledR}$ tomographer, it is shown that PTK, by removing abnormal material and obtaining a smooth surface for basement membrane regeneration, is an effective treatment for epithelial basement membrane dystrophy, improving patient discomfort and visual status.

\section{Conflicts of interest}

The authors declare no conflicts of interest. 


\section{Ethical disclosures}

Protection of human and animal subjects. The authors declare that no experiments were performed on humans or animals for this study.

Confidentiality of data. The authors declare that they have followed the protocols of their work center on the publication of patient data.

Right to privacy and informed consent. The authors have obtained the written informed consent of the patients or subjects mentioned in the article. The corresponding author is in possession of this document.

\section{References}

1. Weiss J, Moller H, Lisch W, Kinoshita S, Aldave A, Belin M. IC3D Classification of the Corneal Dystrophies-Edition 2. Cornea. 2015;34:117-59.

2. Barraquer RI, de Toledo MC, Torres E. Distrofia o queratopatía de la membrana basal epitelial. Atlas y texto 5. Barcelona: Espaxs; 2004:52-6.
3. Cárdenas Díaz T, Guerra Almaguer M, Cruz Izquierdo D, Pérez Suárez RG, Machado Fernández E, Mariño Hidalgo $O$. Principios para realizar queratectomía fototerapéutica. Rev Cubana Oftalmol. 2016;29:652-62.

4. Maldonado López MJ. PTK: queratectomía fototerapéutica. En: Benítez del Castillo Sánchez JM, Durán de la Colina JA, Rodríguez Ares MT, editores. Superficie ocular. Madrid: Sociedad Española de Oftalmología; 2004. p. 329-58

5. Das S, Seitz B. Recurrent corneal erosion syndrome. Surv Ophthalmol. 2008;53:3-15

6. Sharma N, Prakash G, Sinha R, Tandon R, Titiyal JS, Vajpayee RB. Indications and outcomes of phototherapeutic keratectomy in the developing world. Cornea. 2008;27:44-9.

7. Wang L, Tsang $\mathrm{H}$, Coroneo M. Treatment of recurrent corneal erosion syndrome using the combination of oral doxycycline and topical corticosteroid. Clin Exp Ophthalmol. 2008;36:8-12.

8. Ramamurthi S, Rahman MQ, Dutton GN, Ramaesh K. Pathogenesis, clinical features and management of recurrent corneal erosions. Eye. 2006;20:635-44.

9. Rathi VM, Taneja M, Murthy SI, Bagga B, Vaddavalli PK, Sangwan VS. Phototherapeutic keratectomy for recurrent granular dystrophy in postpenetrating keratoplasty eyes. Indian J Ophthalmol. 2016;64:140-4.

10. Pogorelov $P$, Langenbucher A, Kruse F, Seitz B. Long-term results of phototherapeutic keratectomy for corneal map-dot-fingerprint dystrophy (Cogan-Guerry). Cornea. 2006;25:774-7.

11. Rapuano CJ. Excimer laser phototherapeutic keratectomy in eyes with anterior corneal dystrophies: short-term clinical outcomes with and without an antihyperopia treatment and poor effectiveness of ultrasound biomicroscopic evaluation. Cornea. 2005;24:20-31. 